\title{
Geriatric and Student Perceptions Following Student-led Educational Sessions
}

\author{
Kristin M. Janzen, PharmD, BCPS ${ }^{a, b}$; Lauren N. Kormelink, PharmD'; Lindsay M. Saum, PharmD, BCPS, BGCPa,d; Sarah A. Nisly, PharmD,
} BCPS, FCCP ${ }^{e, f}$

${ }^{a}$ Butler University, Indianapolis, IN; ${ }^{b}$ Indiana University Health, Indianapolis, IN; ${ }^{C}$ University of Kentucky HealthCare, Lexington, KY;

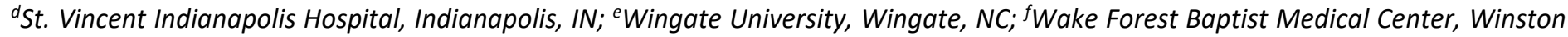
Salem NC

This work was supported by a Butler University Innovation Fund grant.

\begin{abstract}
Objective: The objective of this study was to measure the effect of student-led educational events on geriatric patient and student participant perceptions in a community setting.

Methods: Students led three events at a senior community center, focused on learning and memory, sleep hygiene, and arthritis pain. The participants were geriatric patients who themselves were providers of support to homebound peers ("clients") through an independently organized program. Geriatric participants completed pre-and post-event surveys to measure changes in familiarity with the topics. Student participants also completed pre-and post-event surveys that tracked changes in their comfort in working with the geriatric population.

Results: Each event demonstrated at least one positive finding for geriatric patients and/or their clients. Students reported increased comfort in working with and teaching the geriatric population following the first and third events, but not the second.

Conclusion: Student-led educational sessions can improve perceived health-related knowledge of geriatric participants while simultaneously exposing students to the geriatric patient population. Overall, both students and geriatric participants benefited from these events.

Practice Implications: Incorporation of single, student-led educational events could be mutually beneficial to students and the elderly population in the community and easily incorporated into any healthcare curriculum.
\end{abstract}

Keywords: student-led education; interactive educational sessions; student perceptions; geriatrics

\section{Introduction}

As the population of the United States ages, the need for comprehensive geriatric care is of increasing importance. Integration of geriatric-focused coursework is one piece of a larger responsibility shared by medical, pharmacy, and allied health-services educators today. Additional live interactions are also necessary to overcome stereotypes and enhance students' comfort with the aging population. Educational programming has shown to be effective in elderly patients and is an opportunity to expose students to elderly patients in a way that can be mutually beneficial. A review of patient education studies focusing on arthritis showed that education can lead to a $15-30 \%$ improvement in symptoms. ${ }^{1}$ A fall prevention program for elderly patients led by allied health care professions students was shown to be effective in functional balance and strength through a combination of educational activities and exercise program. ${ }^{2}$

Corresponding Author: Kristin M. Janzen, PharmD, BCPS 4600 Sunset Blvd, Indianapolis, IN 46208

Phone: 317-962-9363; Email: kjanzen@butler.edu
Research has shown a positive correlation between improved attitudes of pharmacy learners and communication with geriatric patients. ${ }^{3-6}$ What remains a question is the impact of interactions between pharmacy students and the aging population on the geriatric patients themselves. Delivery of quality health-related education, in a patient-friendly manner, is the quintessential role of a pharmacist. Pharmacy students are capable of providing effective patient education in the community, as evidenced by a study examining the effects of pharmacy student-led educational games on a variety of healthcare topics in the homeless population. Participants reported increases in understanding and knowledge about each topic following the sessions. ${ }^{7}$ Changes in learner perceptions matter little if the material does not impact the patient population of interest. The literature on the educational impact of student-led interactions with geriatric patients is sparse. ${ }^{8}$ A need exists to evaluate the efficacy of student-driven education within the geriatric community.

The objective of this analysis was to evaluate whether geriatric patients exhibited an increased understanding and familiarity with the topics of memory/learning retention, sleep hygiene, 
and arthritis pain following interactive sessions with pharmacy students.

\section{Methods}

The three main outcomes assessed during this study were the change in the geriatric population's perceptions of the importance of the topic covered, geriatric participants' selfassessed knowledge, and student perceptions of the geriatric population following each student-led educational session.

This study was conducted with the Indianapolis Catholic Charities Senior Companion Program, which pairs community seniors with homebound "clients" to provide one-on-one care and companionship. The geriatric participants were the community seniors that visit the homebound "clients." There were a total of three student-led educational sessions, each focused on a specific topic. Topics were identified by leadership within the Catholic Charities organization. In addition to the geriatric participants, students from three schools of pharmacy (Butler, Purdue and Manchester Universities) participated in the sessions. The program was funded through a Butler University Innovation Fund Grant. The cohort of student and geriatric participants varied for each of the three events and all participation was optional; elderly community center visitors were allowed to partake in activities and/or receive educational handouts without consenting to be study participants, and likewise, student pharmacists were not required to participate as a part of academic requirements. During the first session, informed consent was obtained for the geriatric participants. At subsequent sessions, completion of informed consent for continuing geriatric participants was verified and obtained for any new participants. Student informed consent was obtained at each session, regardless of whether the students volunteered at earlier events.

Based on prior experience with the study group, changes in perception were used to increase activity engagement while still determining the impact of the intervention. At events before this study, the participants were less involved in the activities when there were objective assessments, such as quizzes. Due to this, perception surveys were developed in conjunction with the Catholic Charities leadership and the investigators. Goals of each session were to give the study participants information that could be useful to themselves as well as to the homebound "clients" that they visited each week. Because only the study participants were at the events, perceptions on the impact for the homebound "clients" and the participants' own health was deemed the most appropriate way to evaluate the events.
Pre- and Post-Event Surveys

Geriatric Participants

The outcomes were measured by pre- and post-event surveys of the elderly participants. The surveys utilized a 5-point Likerttype scale ranging from strongly disagree (1) to strongly agree (5). The elderly participants completed the same survey before and after each session, except that the post-event survey included two additional open-ended questions. The survey (Table 1) measured the impact of the topic on the participants' daily life, the participants' and their medical provider's prior discussions, and general perceptions on the education and how it was expected to affect their homebound clients. Eventspecific feedback in the form of open-ended comments was also gathered during the field surveys, in an effort to improve the design and execution for future events.

\section{Student Participants}

The student participants completed a survey with three questions on the pre-and post-event survey, with additional open-ended. The questions asked the students to rank their comfort working with and teaching the elderly population and their perceptions of the dependence level in the elderly population.

\section{Statistical Analysis}

Pre- and post-survey results were compared utilizing Wilcoxon ranked-sum analysis and utilized a p-value of $<0.05$. Statistical analysis was completed utilizing SPSS version 22 .

\section{Educational Sessions}

The student participants were responsible for facilitating each activity for the different sessions. Prior to the session, they were required to attend an orientation led by faculty and student event coordinators, in which they practiced the different activities and discussed the topics that would be taught at the session in detail. The students were given a manual for each session with instructions for the activities. During all three sessions, the elderly participants were given a handout summarizing the session's topic and a small door prize for participation. Additionally, there were prizes for the winners of each session game. Each program ran approximately two hours, including time for student volunteers and seniors to meet and socialize before the educational event began.

\section{Memory and Learning}

The first program, focused on memory and learning retention, divided the participants into three groups that rotated through three stations during the event. The stations were differentiated by topic: facts and myths about dementia, differences between the normal process of aging and warning signs of Alzheimer's disease, and common misconceptions about memory loss and Alzheimer's disease. The information at 
each station was delivered in the form of interactive games to engage participation and enhance retention.

\section{Sleep Hygiene}

In the second session, participants took part in a game-show style activity regarding non-pharmacologic treatments for insomnia. The participants answered questions pertaining to causes, treatment, and prevention of insomnia. Again, the information was presented in an interactive manner to enhance learning and retention.

\section{Arthritis Pain}

The third program covered arthritis pain, including stretches and exercises to help alleviate pain. This event consisted of multiple stations each dedicated to specific stretches and exercises that included: chair stretches, wrist and leg exercises, and stretch bands.

\section{Results}

Change in Geriatric Perception of Student-led Educational Sessions

Full results of geriatric participant perception surveys for each education session can be found in Table 1. Specific demographic data was not collected at each event; however, the Senior Companion Program participants are predominantly African American (91\%), female (96\%), and over the age of 70 (58\%). The names of attendees were not tracked, so the number of participants who attended multiple events is unknown. Open-ended comments were positive, with the majority focused on that the participants enjoyed working with and learning from students.

Memory and Learning

Fifty geriatric patients attended the first activity on memory and learning. Statistical significance was noted for Item 2 concerning impact on the homebound client's day-to-day activities $(p=0.011)$.

\section{Sleep Hygiene}

The second educational session had 53 geriatric participants present to learn about sleep hygiene. Statistical significance was observed on Item 4, which assessed confidence in knowledge about sleep hygiene $(p=0.049)$ and Item 5 , which assessed the participant's ability to recommend activities to homebound clients to improve sleep hygiene $(p=0.034)$.

\section{Arthritis Pain}

Forty-five participants were present for the third educational session about arthritis pain. Statistical significance was shown from pre-survey to post survey results for Item 1 and 2 regarding impact on daily life and activities of geriatric participant $(p<0.001)$ and impact on daily lives of the homebound clients $(p=0.029)$. Statistical significance was also noted with Item 3, assessing previous physician discussion of arthritis $(p=0.001)$ and Item 7 concerning the participants' desire to learn more about arthritis $(p=0.009)$.

\section{Changes in Student Perceptions}

Full results of student surveys for each education session can be found in Table 2 .

Memory and Learning

During the first session on memory and learning, 12 students participated in conducting the educational activities. An improvement was noted in students' comfort in working with $(p=0.005)$ and teaching $(p=0.008)$ geriatric patients.

\section{Sleep Hygiene}

The second session, focusing on sleep hygiene, included 15 student volunteers. No statistically significant changes from baseline occurred regarding students' perceptions of geriatric patients in any of the survey items.

\section{Arthritis Pain}

A total of 13 student volunteers participated in the final educational session about arthritis pain. Similar to the first event, students' survey responses showed a statistically significant difference from pre-survey to post-survey regarding comfort working with $(p=0.006)$ and teaching $(p=0.004)$ geriatric patients. Additionally, statistical significance was achieved from pre-survey to post-survey response regarding the belief that geriatric patients can be independent $(p=0.003)$.

\section{Discussion and Conclusion \\ Discussion}

While many studies have examined the effects of interactions with the elderly on students, this study also addresses the effect of these interactions on the elderly themselves. ${ }^{3-6}$ Students were successful in increasing patients' perceptions of their healthcare knowledge of covered topics in several areas. When comparing the results of pre- and post-event surveys, statistical significance was reached in at least one item in all three events. One unique facet of this current analysis is the potential impact of these sessions on the homebound clients of the geriatric participants. Information gathered at these sessions may be carried forward to impact the health and knowledge of those elderly restricted to home care.

Each specific event showed promising results for the elderly population. Elderly participants demonstrated positive changes in their perceived ability to impact homebound clients' day-today lives after the memory and learning and arthritis pain events. For the sleep hygiene event, patients felt more comfortable in their knowledge and more confident making recommendations regarding sleep to their homebound clients. The arthritis event saw the largest effect on the participants 
themselves, with patients reporting that the event impacted their daily lives and spurred interest in learning more about exercise. Additionally, elderly participants reported that they enjoyed working with the students in the open-ended comments portion of the survey.

Many statistically significant results showed no change in the median values between pre- and post-surveys, signifying less variance in the overall response. One question (Item 2, sleep event) had identical medians and interquartile range (IQR) but reached statistical significance. These results are due to the change in frequency of each specific Likert value and, though statistically significant, may not be clinically relevant.

The topics, which were chosen by the investigators in conjunction with the Catholic Charities leadership, had very high pre-survey scores, indicating baseline comfort with those areas. In the future, choosing topics that geriatric participants feel less comfortable with could allow for more clinically relevant changes. The changes in response between the events could be due to the amount of patients that were personally affected by these conditions. Though specific medical history data is not available for the participants or their homebound clients, it is likely that a number of participants visit clients with memory and sleep problems. Likewise, with a statewide prevalence of $54 \%$ in adults aged over 65 years, it is likely that many participants suffer from arthritis themselves. ${ }^{9}$

In accordance with existing literature, students reported increased comfort and confidence in working with the elderly after participation in an event. ${ }^{3-6}$ With focused training prior to the event, students were able to successfully teach elderly participants non-pharmacologic strategies to improve their daily lives, and possibly to extend that effect to their homebound clients. Baseline comfort among the pharmacy students in this study was higher than anticipated. This could be indicative of volunteer bias - participants who signed up to volunteer at the event were likely more comfortable and/or excited to work with this population than were those who did not attend the events.

There are several limitations to this study. Increase in knowledge of the topics covered in the sessions was selfreported, and no objective measures were performed to identify the extent of this learning. Some responses might have been biased because of a lack of understanding of the topic title - for example, there was an increase in the number of participants who reported speaking to their primary care practitioner about sleep hygiene after the event, even though they had clearly not seen this provider during the event. This could demonstrate survey fatigue or a lack of understanding prior to starting the event. Demographic data was not collected for either the volunteers or participants. This information could be utilized in the future to target topics that might be helpful to the participants. Finally, neither frequency of student volunteering nor elderly participant attendance was tracked, so some participants may have volunteered or attended multiple events.

Despite the aforementioned limitations, several important lessons can be learned from this analysis. Integration of healthcare learners into the community can provide an enriching experience for both groups in a service-learning atmosphere. Detailed material should be provided to the students before the event, and an interactive training session can increase comfort with the activity. Topics should be tailored to the specific group of participants to maximize impact, which might require discussion with community leaders or a survey of the participants. The interactive games that were utilized in this study were simple to understand, encouraged participation, and were well received by geriatric participants. The effect of this method as opposed to more traditional formats for educational programming could be an area of future study.

\section{Conclusion}

Exposure to elderly patients in a community setting was beneficial to both pharmacy students and the seniors who participated in the educational events. Elderly participants benefited from the events, according to their self-reported perceptions, with impacts to either their own or their homebound clients' daily lives. Students felt increased comfort in working with the geriatric population and felt that their ability to teach this age group had improved. Events such as these could provide students with invaluable exposure while also improving health and wellness in the community.

\section{Practice Implications}

This study demonstrates that senior participants found interactions with students beneficial and enjoyable. Additionally, it highlighted the importance for student exposure and practice in working with the elderly population. Attendance at the events led to increased comfort in providing education to seniors, which will be an essential skill after graduation. Incorporating these types of activities into the didactic curriculum should be considered to increase student pharmacist comfort and competence in educating the elderly.

Acknowledgments: The authors thank Thomas Fehn, PharmD and Kayla Goodwine, PharmD for their assistance in data collection and project execution. 


\section{References}

1. Hirano PC, Laurent DD, Lorig K. Arthritis patient education studies, 1987-1991: a review of the literature. Patient Educ Couns. 1994;24:9-54.

2. Der Ananian CA, Mitros M, Buman MP. Efficacy of a student-lef community-based, multifactorial fall prevention program: Stay in Balance. Front Public Health. 2017;5:Article 30.

3. Adkins DM, Mayhew SL, Gavaza P, Rahman S. Pharmacy students' attitudes toward geriatric nursing home patients. Am J Pharm Educ. 2012;76:Article 81.

4. Martin BA, Porter AL, Shawl L, Motl Moroney SE. A model for partnering first-year student pharmacists with community-based older adults. Am J Pharm Educ. 2012;76:Article 85.

5. Mobley Smith MA, Koronkowski MJ, Petersen NM. Enhancing student learning through integrating community-based geriatric educational outreach into ambulatory care advanced practice experiential training. Am J Pharm Educ. 2004;68:Article 20.

6. Dy-Boarman E, Martin D, Nisly SA. Use of a health screening and education event to change student attitudes towards the elderly. Curr Pharm Teach Learn. 2017;9(1):101-7.

7. Beggs AE, Karst AC. Effectiveness of pharmacy student-led health education in adults experiencing homelessness. J Health Care Poor Underserved. 2016;27:954-60.

8. Eaton J, Donaldson G. Alternating nursing student and older adult attitudes through a possible selves ethnodrama. J Prof Nurs. 2016;32:141-51.

9. Behavioral Risk Factor Surveillance System: Indiana Arthritis Prevalence. Centers for Disease Control and Prevention.

https://www.cdc.gov/arthritis/data_statistics/statedata/Indiana.html. Updated March 27, 2017.

Accessed September 4, 2017. 


\begin{tabular}{|c|c|c|c|c|c|c|c|c|c|c|}
\hline \multirow[b]{2}{*}{$\begin{array}{l}\text { Survey } \\
\text { Item }\end{array}$} & \multirow[b]{2}{*}{ Survey Question } & \multicolumn{3}{|c|}{$\begin{array}{l}\text { Event 1: Memory and Learning } \\
(\mathrm{n}=50)\end{array}$} & \multicolumn{3}{|c|}{$\begin{array}{c}\text { Event 2: Sleep } \\
(n=53)\end{array}$} & \multicolumn{3}{|c|}{$\begin{array}{l}\text { Event 3: Arthritis Pain } \\
(n=45)\end{array}$} \\
\hline & & $\begin{array}{l}\text { Pre-Event } \\
\text { Median, } \\
\text { IQR }\end{array}$ & $\begin{array}{c}\text { Post- } \\
\text { Event } \\
\text { Median, } \\
\text { IQR }\end{array}$ & P-Value & $\begin{array}{c}\text { Pre- } \\
\text { Event } \\
\text { Median, } \\
\text { IQR }\end{array}$ & $\begin{array}{l}\text { Post-Event } \\
\text { Median, } \\
\text { IQR }\end{array}$ & P-Value & $\begin{array}{l}\text { Pre-Event } \\
\text { Median, } \\
\text { IQR }\end{array}$ & $\begin{array}{c}\text { Post- } \\
\text { Event } \\
\text { Median, } \\
\text { IQR }\end{array}$ & P-Value \\
\hline 1 & $\begin{array}{c}\text { This topic has impacted my daily life } \\
\text { and my day-to-day activities. }\end{array}$ & 4,2 & 5,1 & 0.195 & 4,1 & 4,2 & 0.063 & 3,2 & 5,1 & $<0.001^{*}$ \\
\hline 2 & $\begin{array}{l}\text { This topic has impacted my } \\
\text { homebound client's day-to-day } \\
\text { activities. }\end{array}$ & 4,2 & 5,1 & $0.011^{*}$ & 4,1 & 4,2 & 0.141 & 5,2 & 5,2 & $0.029 *$ \\
\hline 3 & $\begin{array}{l}\text { My primary care physician has } \\
\text { addressed this topic with me before. }\end{array}$ & 3,2 & $3,2.75$ & 0.220 & 3,3 & 4,4 & 1.029 & 4,2 & 5,1 & $0.001 *$ \\
\hline 4 & $\begin{array}{l}\text { I feel confident about my knowledge } \\
\text { about this topic. }\end{array}$ & $4.5,1$ & $4.5,1$ & 0.115 & 4,2 & 4,1 & $0.049 *$ & 5,1 & 5,1 & 0.099 \\
\hline 5 & $\begin{array}{l}\text { I would be able to recommend } \\
\text { activities to my homebound client } \\
\text { on this topic. }\end{array}$ & 4,1 & 5,1 & 0.066 & 4,2 & 4,1 & $0.034^{*}$ & 4,1 & 5,1 & 0.350 \\
\hline 6 & $\begin{array}{l}\text { This topic is important for a patient } \\
\text { of advanced age. }\end{array}$ & 5,1 & 5,1 & 0.097 & 5,1 & 5,1 & 0.516 & 5,1 & 5,1 & 0.231 \\
\hline 7 & $\begin{array}{c}\text { I have a desire to learn more } \\
\text { information about this topic in the } \\
\text { future. }\end{array}$ & 5,1 & 5,1 & 0.369 & 4,1 & 4,1 & 0.847 & 4,2 & 5,1 & $0.009 *$ \\
\hline 8 & $\begin{array}{l}\text { This topic has an impact on a } \\
\text { patient's overall health. }\end{array}$ & 5,1 & 5,1 & 0.096 & 5,1 & 5,1 & 0.680 & 5,1 & 5,1 & 0.346 \\
\hline
\end{tabular}

*denotes statistically significant result

Table 2: Results from Student Participants

\begin{tabular}{|c|c|c|c|c|c|c|c|c|c|c|}
\hline \multirow[b]{2}{*}{$\begin{array}{l}\text { Survey } \\
\text { Item }\end{array}$} & \multirow[b]{2}{*}{ Survey Question } & \multicolumn{3}{|c|}{ Event 1: Memory and Learning $(n=12)$} & \multicolumn{3}{|c|}{$\begin{array}{l}\text { Event 2: Sleep } \\
\qquad(n=15)\end{array}$} & \multicolumn{3}{|c|}{$\begin{array}{l}\text { Event 3: Arthritis Pain } \\
\qquad(n=13)\end{array}$} \\
\hline & & $\begin{array}{l}\text { Pre-Event } \\
\text { Median, } \\
\text { IQR }\end{array}$ & $\begin{array}{c}\text { Post-Event } \\
\text { Median, } \\
\text { IQR }\end{array}$ & P-Value & $\begin{array}{l}\text { Pre-Event } \\
\text { Median, } \\
\text { IQR }\end{array}$ & $\begin{array}{c}\text { Post- } \\
\text { Event } \\
\text { Median, } \\
\text { IQR }\end{array}$ & P-Value & $\begin{array}{l}\text { Pre-Event } \\
\text { Median, } \\
\text { IQR }\end{array}$ & $\begin{array}{l}\text { Post- } \\
\text { Event } \\
\text { Median, } \\
\text { IQR }\end{array}$ & P-Value \\
\hline 1 & $\begin{array}{c}\text { I am comfortable working with } \\
\text { the geriatric population. }\end{array}$ & $4,0.25$ & 4,1 & $0.005^{*}$ & 4,1 & 5,1 & 0.480 & 4,1 & 5,0 & $0.006^{*}$ \\
\hline 2 & $\begin{array}{l}\text { I view the geriatric population as } \\
\text { independent. }\end{array}$ & 2,1 & 2,2 & 0.102 & $3,0.5$ & 4,1 & 0.187 & 3,0 & 4,0 & $0.003^{*}$ \\
\hline 3 & $\begin{array}{l}\text { I am comfortable teaching the } \\
\text { geriatric population. }\end{array}$ & $3,0.25$ & 4,1 & $0.008^{*}$ & 4,0 & 5,1 & 0.054 & 4,1 & 5,1 & $0.004 *$ \\
\hline
\end{tabular}

*denotes statistically significant result 